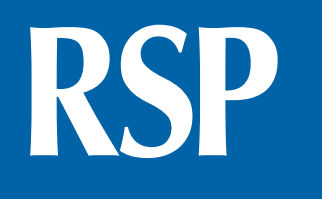

http://www.rsp.fsp.usp.br/
Revista de Saúde Pública

\section{Locomotor activity in Aedes aegypti with different insecticide resistance profiles}

\author{
Bruno Magalhães Nakazato' (iD, Maria de Lourdes da Graça Macoris" iD, Paulo Roberto \\ Urbinatti"' iD, Tamara Nunes Lima-Camara"'I iD \\ I Universidade de São Paulo. Faculdade de Saúde Pública. Programa de Pós-Graduação em Saúde Pública. \\ São Paulo, SP, Brasil \\ "Superintendência de Controle de Endemias. Laboratório de Entomologia Aplicada. Marília, SP, Brasil \\ III Universidade de São Paulo. Faculdade de Saúde Pública. Departamento de Epidemiologia. São Paulo, SP, Brasil
}

\section{ABSTRACT}

OBJECTIVE: To evaluate locomotor activity in four field populations of Ae. aegypti with different insecticide resistance profiles from the state of São Paulo for two years.

METHODS: This study comprised the susceptible Rockefeller strain and four populations from São Paulo, Brazil: two considered populations with "reduced susceptibility" to pyrethroids (Campinas and Marília), and two "resistant populations" (Santos and Ribeirão Preto). First, 2016 and 2017 eggs from these five populations were hatched in laboratory. Virgin females underwent experiments under laboratory conditions at $25^{\circ} \mathrm{C}$, with $12: 12 \mathrm{~h}$ light/dark (LD) photoperiod; 24-hour individual activity was recorded using a locomotor activity monitor (LAM).

RESULTS: In females from 2016 field populations, both resistant populations showed significant more locomotor activity than the two reduced susceptibility populations and the Rockefeller strain $(\mathrm{p}<0.05)$. As for females from 2017 field populations, reduced susceptibility populations showed a significant increased locomotor activity than the Rockefeller strain, but no significant difference when compared to Santos resistant population $(\mathrm{p}>0.05)$.

CONCLUSIONS: Our results indicate that insecticide-resistant Ae. aegypti populations show increased locomotor activity, which may affect the transmission dynamics of their arboviruses.

DESCRIPTORS: Aedes. Insecticide Resistance. Locomotion. Disease Vectors.

\footnotetext{
Correspondence:

Tamara Nunes Lima Camara

Faculdade de Saúde Pública da USP Avenida Doutor Arnaldo, 715

E-mail: limacamara@usp.br

Received: Jun 16, 2020

Approved: Oct 1, 2020

How to cite: Nakazato BM, Macoris MLG, Urbinatti PR, Lima-Camara TN. Locomotor activity in Aedes aegypti with different insecticide resistance profiles. Rev Saude Publica. 2021;55:18.

https://doi.org/10.11606/s15188787.2021055002809
}

Copyright: This is an open-access article distributed under the terms of the Creative Commons Attribution License, which permits unrestricted use, distribution, and reproduction in any medium, provided that the original author and source are credited. 


\section{INTRODUCTION}

Aedes (Stegomyia) aegypti (Linnaeus, 1762) is a mosquito highly adapted to the urban environment, often found inside human dwellings and their surrounding $\mathrm{s}^{1-3}$. This diurnal and anthropophilic species is the primary vector of several arboviruses, such as dengue, chikungunya, and Zika - all mainly transmitted to humans through the bite of an infected female Ae. aegypti ${ }^{3}$.

Among the measures adopted to control Ae. Aegypti, using chemical insecticides has been proposed as chemical control, eliminating or relocating breeding sites as mechanical control and applying Bacillus thuringiensis insraelensis (Bti) larvicide as biological control' ${ }^{4}$. With dichloro-diphenyl trichloroethane (DDT) development in 1939 new prospects loomed regarding the species, including its eradication in Brazil and neighboring countries by $1958^{5-7}$. In general, all chemical insecticide classes act on mosquito's central nervous system (CNS), inducing the "knockdown effect".

Besides the organochlorine class (OC), which contains DDT, chemical organophosphate (OP), carbamate (CA), and pyrethroid (PY) insecticides are also used against Ae. aegypti and other mosquito vectors ${ }^{8,9}$. Whereas $\mathrm{OC}$ and PY act by destabilizing the balance and passage of sodium and potassium ions though the voltage-gated sodium channel $(\mathrm{NaV})^{10}$, OP and CA act by phosphorylating acetylcholinesterase (AChE), preventing acetylcholine (Acetyl-COA) degradation and thus disrupting the following neuron action potential ${ }^{8}$.

The massive use of chemical insecticides may lead different Ae. aegypti populations to develop resistance. The first case of DDT-resistance in Ae. aegypti populations was reported in Cúcuta, Colombia, in 1957. Besides resistance, DDT also incur a long residual action in the environment, affecting agriculture and aquatic ecosystems, besides having a hazardous effect on human health, so that its use in the Americas declined in the early $1970 \mathrm{~s}^{9,11}$.

In Brazilian Ae. Aegypti populations, insecticide resistance was first observed in 1994, with reduced susceptibility to organophosphates ${ }^{12}$. Due to Ae. aegypti decreased sensitivity to PY and OP, several populations of this mosquito have been monitored in São Paulo ${ }^{12}$, indicating high levels of PY resistance, especially in the cities of Santos and Ribeirão Preto ${ }^{13,14}$, highly urbanized areas. In turn, Ae. aegypti populations from Marília and Campinas showed low levels of PY-resistance and susceptibility to OP insecticides ${ }^{13,14}$.

The World Health Organization (WHO) classifies mosquitoes susceptibility profile according to mortality, as follows: $>98 \%$ mortality is deemed susceptible; $<98 \%$ as suspected resistance; $90-97 \%$ as suspected presence of resistant genes; and $<90 \%$ as confirmed presence of resistant genes ${ }^{15}$. Mosquito vectors acquire resistance to PY through the structural alteration of specific genes due to random and non-synonymous substitutions, encoding altered target proteins and reducing insecticides molecules binding ${ }^{16}$. Such mutations, known as "knockdown resistance" (Kdr), were first detected in Musca domestica as a leucine-to-phenylalanine substitution ( $L 1014 F)$ and are passed down to new generations ${ }^{16,17}$. Two mutations are widespread among Brazilian Ae. aegypti populations: phenylalanine-to-cysteine (F1534C) and valine-to-isoleucine (V1016I) substitution - both related to the phenotypic profile of pyrethroid resistance ${ }^{14,18,19}$.

The daily activities of mosquito vectors, such as mating, blood-feeding, flight, and oviposition, are controlled by a circadian $\operatorname{clock}^{20}$. Ae. aegypti often present a diurnal and bimodal locomotor activity, with morning and afternoon peaks ${ }^{2}$. However, insemination, blood-feeding ${ }^{21}$, and dengue infection ${ }^{22}$ may influence this species' locomotor activity and consequently its arbovirus transmission dynamics ${ }^{23}$. Brito et al. (2013) found Ae. aegypti with $K d r$ mutations to show a significant increase in locomotor activity when compared to the Rockefeller strain ${ }^{24}$. Considering that, studies evaluating the locomotor activity of resistant populations are necessary for providing a better understanding of the effects of insecticide resistance on Ae. aegypti locomotor activity. 
We assess the hypothesis that insecticide-resistant Ae. aegypti populations present an increased locomotor activity, potentially favoring arboviruses transmission dynamics. This study sought to assess locomotor activity of four Ae. aegypti populations with different insecticide resistance profiles from the state of São Paulo over two years.

\section{METHODS}

\section{Population Profiles}

Aedes aegypti populations from São Paulo, Brazil, were selected by the phenotype profile of insecticide resistance. Based on bioassays tests ${ }^{14}$ and following WHO criteria ${ }^{15}$, populations

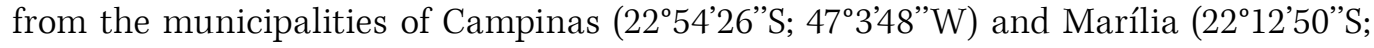
$49^{\circ} 56^{\prime} 45^{\prime \prime} \mathrm{W}$ ) were considered as presenting "reduced susceptibility" to pyrethroid (PY), whereas populations from Santos ( $23^{\circ} 56^{\prime} 41^{\prime \prime}$; $46^{\circ} 19^{\prime} 49^{\prime \prime} \mathrm{W}$ ) and Ribeirão Preto ( $21^{\circ} 10^{\prime} 39^{\prime} \mathrm{S} ; 47^{\circ} 48^{\prime} 37^{\prime \prime} \mathrm{W}$ ) were considered "resistant" (Figure 1). We also tested the Rockefeller strain (from the Centers for Disease Control and Prevention-CDC, San Juan, Puerto Rico), a laboratory reference strain susceptible to insecticides and frequently used for monitoring Ae. aegypti field populations biological responses ${ }^{13}$. For presenting a $>98 \%$ mortality to pyrethroids (susceptible), this strain enables the comparison with reduced-susceptibility and resistant populations. Ae. aegypti populations from 2016 and 2017 underwent experiments, except for Ribeirão Preto, which was only tested in 2016. Eggs were collected using ovitraps during Spring - the pre-epidemic season. The susceptibility/resistance status of non-blood-fed female Ae. aegypti (2-5 days old) was evaluated based on mortality rates obtained from bioassays using insecticide-impregnated papers, according to WHO methodology $\mathrm{y}^{14,15}$. Insecticide dose was established as the double of 99\% lethal dose obtained to a susceptible strain.

\section{Mosquito Rearing}

For hatching, eggs from each population were placed in $10 \times 10 \times 5 \mathrm{~cm}$ labeled trays containing $400 \mathrm{~mL}$ of tap water and $0.2 \mathrm{mg}$ of fish food (Tetramin ${ }^{\circ}$. Larvae were kept in $30 \times 20 \times 5 \mathrm{~cm}$ labeled trays with $1 \mathrm{~L}$ of tap water and $20 \mathrm{mg}$ of fish food. Hatching trays were kept in an incubator at $25^{\circ}$ Celsius and $70 \%$ relative humidity with 12 hours of light and 12 hours of dark (LD 12:12). All pupae were placed in individual small containers
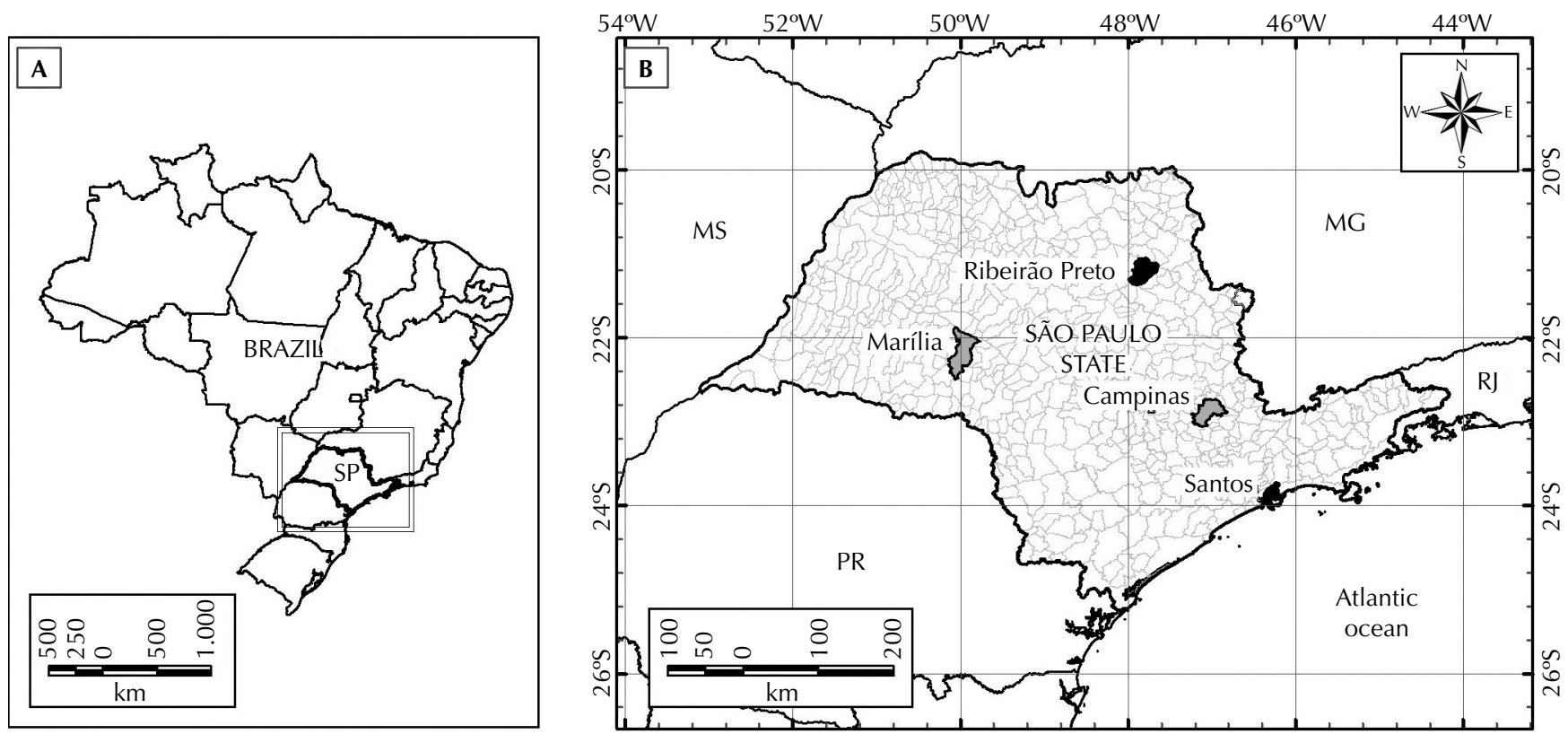

Figure 1. Ae. aegypti population profile according to insecticide resistance. (A) Brazil Map highlighting the state of São Paulo. (B) São Paulo municipalities with the Ae. aegypti populations tested. Reduced susceptibility to pyrethroids (grey - Campinas and Marília) and resistant (black - Santos and Ribeirão Preto). 
with $5 \mathrm{~mL}$ of tap water until emergence, ensuring virgin females. Then, females from each population were transferred to labeled cages and kept in the same incubator under the same photoperiod, temperature, and humidity as the rearing phase.

\section{Analysis of Locomotor Activity}

Three-to-four-days-old females from all tested populations (Campinas, Marília, Santos, Ribeirão Preto and Rockefeller) were anesthetized in ice and then placed in individual glass tubes $(1 \mathrm{~cm} \times 10 \mathrm{~cm})$. Adults were fed by a $10 \%$ sucrose-soaked cotton plug. Glass tubes were sealed with Parafilm ${ }^{\circledR}$ and placed in the locomotor activity monitor (TriKinects Inc, Waltham, MA, USA), which was equipped with infrared beam and detectors, counting every time mosquitoes broke the beam and measuring their activity-rest pattern ${ }^{25,26}$. All monitors were placed within a Precision Scientific Incubator Model 818, under LD 12:12 and constant temperature of $25^{\circ} \mathrm{C}$. In our experiments, light functioned as the Zeitgeber (ZT) - a Germanic term that means "time giver" or synchronizer ${ }^{21}$. In a LD 12:12 cycle, for example, ZT02 corresponds to 2 hours after lights are on and ZT14 to 2 hours after lights are off.

Each female's total activity was individually recorded for seven consecutive days, at 30-minute intervals, using the DAMSystem data acquisition software. At least two replicate experiments were conducted for all populations in 2016 and 2017 (except for Ribeirão Preto, which only comprised populations from 2016). Only females that survived until the sixth day of the experiment were analyzed (Table 1), and data from the second to the fifth day of the experiment were used for analysis.

William's mean $(\mathrm{Wm})$ was calculated as an estimate of the central tendency activity during each 30 minute-interval ${ }^{21,16}$. William's mean is a modification of geometric mean related to data log-transformation to accommodate zero values by adding 1 to all data values and then subtracting 1 from the mean ${ }^{27,28}$.

\section{Statistical Analysis}

The means of total activity (24 hours), diurnal activity without lights-on (excluding the first 30 minutes of the diurnal phase lights-on due to the "startle response effect" resulting from the dark-light transition) ${ }^{21}$, and half-day activity (HDA; ZT06 to ZT12 interval) were calculated for each mosquito. Each mosquito mean HDA, calculated using all log $(\mathrm{N}+1)$ values related to every ZT06-ZT12 30-min interval, was employed in statistical analyses. We chose half-day activity for statistical analyses because Ae. aegypti shows

Table 1. Means of female Ae. aegypti locomotor activity according to insecticide resistance profile.

\begin{tabular}{|c|c|c|c|c|c|c|}
\hline \multirow[b]{2}{*}{ Year } & \multirow[b]{2}{*}{ Profile } & \multirow[b]{2}{*}{ Population } & \multirow[b]{2}{*}{$\mathbf{n}$} & \multicolumn{3}{|c|}{ Mean (SD) } \\
\hline & & & & $\begin{array}{c}\text { Total activity } \\
\text { (24h) }\end{array}$ & $\begin{array}{l}\text { Diurnal activity without } \\
\text { lights-on (11.5h) }\end{array}$ & $\begin{array}{c}\text { HDA } \\
\text { (ZT06 to ZT12) }\end{array}$ \\
\hline \multirow[t]{5}{*}{2016} & Reduced & Campinas & $95^{\mathrm{b}}$ & $0.43(0.16)$ & $0.68(0.26)$ & $0.83(0.28)$ \\
\hline & susceptibility & Marília & $104^{\mathrm{b}}$ & $0.43(0.19)$ & $0.62(0.25)$ & $0.79(0.26)$ \\
\hline & \multirow{2}{*}{ Resistant } & Santos & $68^{\mathrm{a}}$ & $0.48(0.17)$ & $0.73(0.25)$ & $0.91(0.28)$ \\
\hline & & Ribeirão Preto & $73^{\mathrm{a}}$ & $0.57(0.21)$ & $0.83(0.30)$ & $0.97(0.29)$ \\
\hline & Susceptible & Rockefeller & $75^{\mathrm{a}}$ & $0.45(0.16)$ & $0.62(0.21)$ & $0.78(0.23)$ \\
\hline \multirow[t]{4}{*}{2017} & Reduced & Campinas & $96^{\mathrm{b}}$ & $0.58(0.20)$ & $0.83(0.31)$ & $0.96(0.33)$ \\
\hline & susceptibility & Marília & $43^{\mathrm{a}}$ & $0.46(0.18)$ & $0.74(0.29)$ & $0.91(0.31)$ \\
\hline & Resistant & Santos & $63^{\mathrm{a}}$ & $0.56(0.20)$ & $0.86(0.32)$ & $1.00(0.35)$ \\
\hline & Susceptible & Rockefeller & $72^{\mathrm{a}}$ & $0.45(0.16)$ & $0.58(0.22)$ & $0.73(0.24)$ \\
\hline
\end{tabular}

$\mathrm{n}$ : total number of individuals tested; SD: standard deviation; HDA: half-day activity.

a Two replicates.

b Three replicates. 
greater activity during this time of the day ${ }^{2,29}$. Previous studies have also used this method to calculate the total, diurnal, and nocturnal Ae. aegypti locomotor activity means for statistical analysis ${ }^{21,27}$.

After calculating mean HDA, the Kolmogorov-Smirnov test was use to assess data normality. Once normality assumptions were satisfied, the parametric independent samples T-test was used to verify differences between replicas of each population in each year (when three replicas were present, one-way ANOVA was used). Independent samples T-test was also used to compare possible differences within the same population between years (temporal variation). One-way ANOVA and Fisher's LSD post-hoc test compared locomotor activity between populations for the two years evaluated and among all five tested populations. Populations with reduced susceptibility or with resistant profile were not grouped for statistical analyses. All statistical analyses were performed in the software Statistical Package for the Social Science (SPSS), version 17, with $\alpha<0.05$.

\section{RESULTS}

We assessed 542 virgin females from four Ae. aegypti field populations (resistant and susceptible) and 147 the Rockefeller strain (Table 1). Table 1 shows the number of females within each tested population for 2016 and 2017 and the means of total activity, diurnal activity without lights-on, and half-day activity (HDA - ZT06 to ZT12 interval). All populations presented higher means in the ZT06-ZT12 interval, when Ae. aegypti showed more locomotor activity.

Figure 2 shows locomotor activity of populations with reduced susceptibility, from Campinas (A) and Marília (B), resistant populations, from Santos (C) and Ribeirão Preto (only 2016) (D), and for the Rockefeller strain (E), all for 2016 and 2017, during the four days of experiment (days 2-5). All populations showed a diurnal and bimodal locomotor activity pattern, peaking at lights-on and near lights-off (Figure $2 \mathrm{~A}-\mathrm{E}$ ).

The 2017 populations from Campinas and Marília showed significantly increased locomotor activity during light phase when compared to 2016 populations (T-test, ZT06 to ZT12 interval; $\mathrm{t}=-2.991, \mathrm{p}=0.003$ and $\mathrm{t}=-2.479, \mathrm{p}=0.014$ respectively), suggesting a temporal variation (Figures $2 \mathrm{~A}$ and B). However, we found no significant differences in the locomotor activity of Santos and Rockefeller populations between 2016 and 2017 (T-test, ZT06 to ZT12 interval; $\mathrm{t}=-1.555, \mathrm{p}=0.122$ and $\mathrm{t}=1.305, \mathrm{p}=0.194$ respectively) (Figures $2 \mathrm{C}$ and $\mathrm{E}$ ). As for Riberião Preto, no temporal comparison was possible as we only had data regarding 2016 (Figure 2D). The replicates of each population in 2016 and 2017 presented no significant difference (ANOVA, $\mathrm{p}>0.05$ and t-test, $\mathrm{p}>0.05$ ).

Table 2 shows Fisher's LSD post-hoc results for Ae. aegypti populations with reduced susceptibility, resistant populations, and Rockefeller strain. In 2016, the Rockefeller strain showed a higher second peak compared to Marilia and Campinas (Figure 3A). However, both reduced susceptibility populations showed no significant difference in ZT06-ZT12 interval means when compared to the Rockefeller strain ( $p=0.234$ and $p=0.815$, respectively) (Table 2). We also verified no significant differences between the populations of Marilia and Campinas $(\mathrm{p}=0.296)$ (Table 2).

Populations from Santos and Ribeirão Preto presented significantly increased locomotor activity when compared to the Rockefeller strain, especially during the anticipation period (from ZT06 to ZT12) (Figure 3B). ZT06-ZT12 interval means were significantly higher in resistant populations than in the reduced susceptibility populations from Campinas ( $\mathrm{p}=0.044$ and $\mathrm{p}<0.001$, respectively) and Marília $(\mathrm{p}=0.003$ and $\mathrm{p}<0.0001$, respectively), and in the Rockefeller strain ( $p=0.003$ and $p<0.0001$, respectively) (Table 2). However, we found no significant difference between the 2016 populations from Santos and Ribeirão Preto $(\mathrm{p}=0.175)$ (Table 2). 

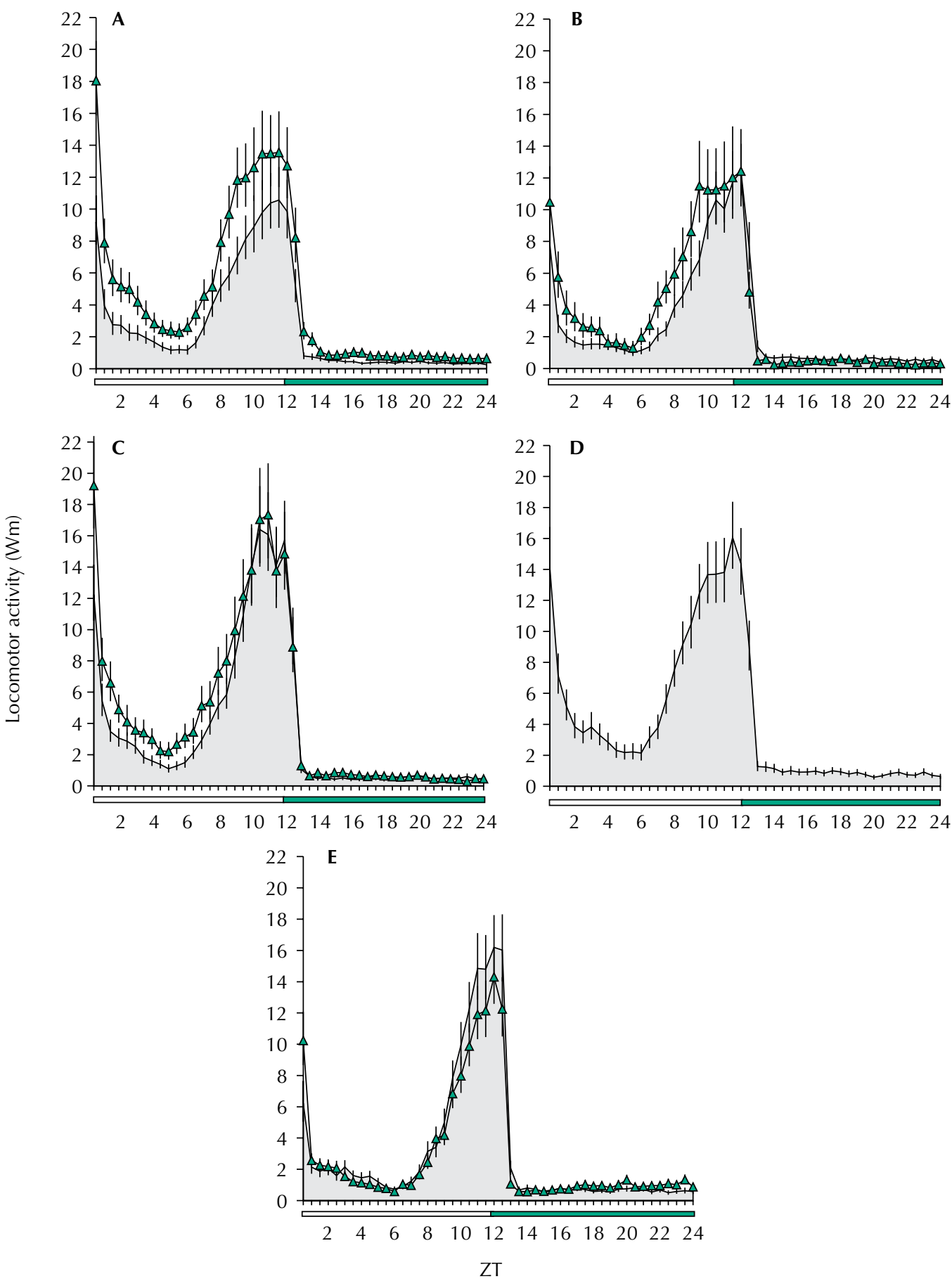

Figure 2. Locomotor activity of Ae. aegypti populations in 2016 and 2017. Locomotor activity of Ae. aegypti populations with reduced susceptibility (A - Campinas and B - Marília), resistant (C - Santos and D - Ribeirão Preto), and Rockefeller strain (E) in 2016 (grey area) and 2017 (line with triangles), under LD 12:12, at $25^{\circ} \mathrm{C}$. Error bars are represented by solid (2016) and dashed (2017) lines. White bar represents the photophase and black bar the scothophase. ZT: Zeitgeber time; ZTO: time the light turns on; ZT12: time the light turns off.

Although 2017 populations from Campinas and Marília showed no significant differences in locomotor activity between them ( $p=0.379)$ (Table 2), when compared to the Rockefeller strain locomotor activity was significantly increased $(p<0.0001$ and $p=0.003$, respectively), especially during the photophase (Figure 3C).

Contrary to 2016, Campinas and Marília populations did not differ significantly from Santos resistant population $(\mathrm{p}=0.446$ and $\mathrm{p}=0.150$, respectively) (Figure 3D; Table 2). Santos population differed significantly from the Rockefeller strain $(\mathrm{p}<0.0001)$. 
Table 2. Comparison between each population half-day activity (ZT06-ZT12) mean in relation to different insecticide resistance profiles.

\begin{tabular}{|c|c|c|c|c|c|c|}
\hline \multirow[b]{2}{*}{ Profile } & \multirow{2}{*}{$\begin{array}{l}\text { Populations } \\
\text { (I versus J) }\end{array}$} & \multicolumn{2}{|l|}{2016} & \multirow{2}{*}{$\begin{array}{l}\text { Populations } \\
\text { (I versus J) }\end{array}$} & \multicolumn{2}{|l|}{2017} \\
\hline & & $\begin{array}{c}\text { Mean } \\
\text { Difference (I-J) }\end{array}$ & p & & $\begin{array}{c}\text { Mean } \\
\text { Difference (I-J) }\end{array}$ & $\mathbf{p}^{\mathrm{a}}$ \\
\hline \multirow{3}{*}{$\begin{array}{l}\text { Reduced } \\
\text { susceptibility/ } \\
\text { Susceptible }\end{array}$} & Camp versus Mar & 0.040 & 0.296 & Camp versus Mar & 0.050 & 0.379 \\
\hline & Camp versus Rock & 0.049 & 0.234 & Camp versus Rock & 0.232 & $<0.001$ \\
\hline & Mar versus Rock & 0.009 & 0.815 & Mar versus Rock & 0.182 & 0.003 \\
\hline \multirow{4}{*}{$\begin{array}{l}\text { Reduced } \\
\text { susceptibility/ } \\
\text { Resistant }\end{array}$} & Camp versus San & -0.085 & 0.044 & Camp versus San & -0.038 & 0.446 \\
\hline & Camp versus Rib & -0.147 & $<0.001$ & Mar versus San & -0.088 & 0.150 \\
\hline & Mar versus San & -0.125 & 0.003 & & & \\
\hline & Mar versus Rib & -0.186 & $<0.001$ & & & \\
\hline \multirow{2}{*}{$\begin{array}{l}\text { Susceptible/ } \\
\text { Resistant }\end{array}$} & San versus Rock & 0.135 & 0.003 & San versus Rock & 0.270 & $<0.001$ \\
\hline & Rib versus Rock & 0.196 & $<0.001$ & & & \\
\hline Resistant & San versus Rib & -0.061 & 0.175 & & & \\
\hline
\end{tabular}

Camp: Campinas; Mar: Marilia; San: Santos; Rib: Ribeirao Preto; Rock: Rockefeller.

${ }^{a}$ Results with ANOVA One-way and Fisher's LSD post hoc test.
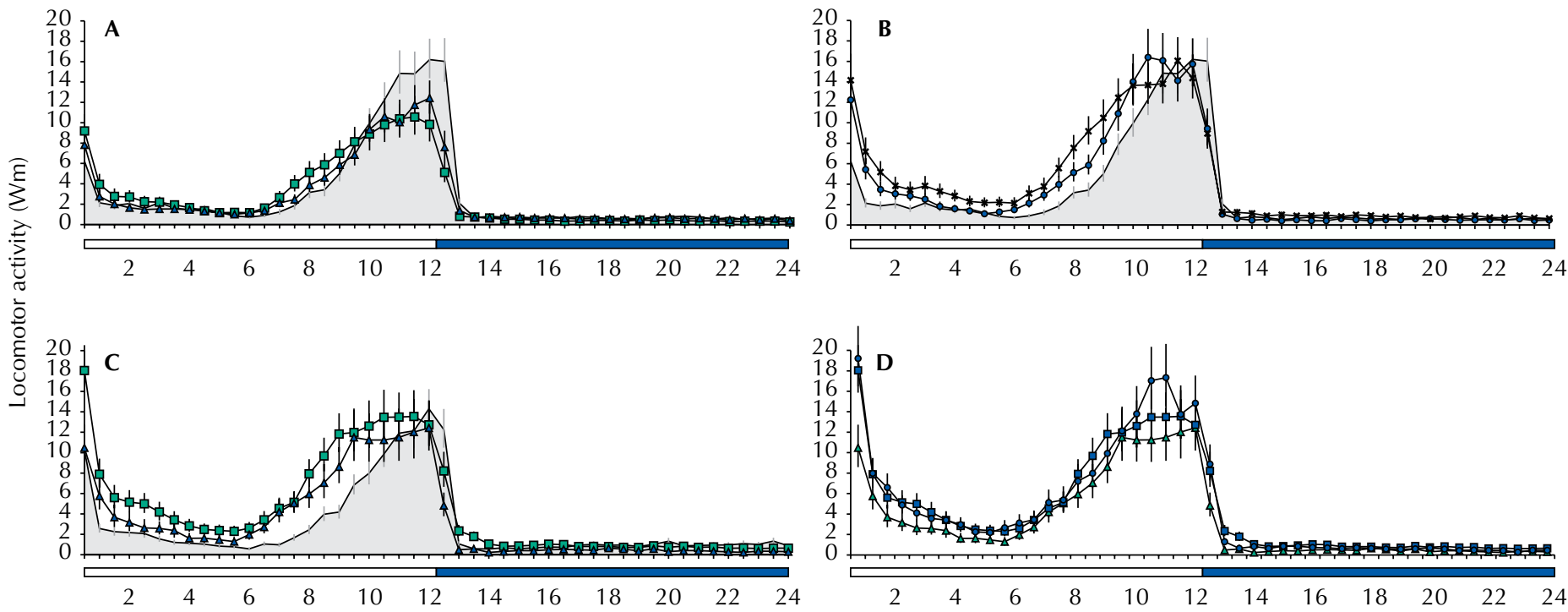

ZT

Figure 3. Locomotor activity of Ae. aegypti populations. 2016: (A) Populations with reduced susceptibility from Campinas (line with squares; error bars, solid line) and Marília (triangles; error bars, dark dashed line); (B) Resistant populations from Santos (circles; error bars, solid line) and Ribeirão Preto (crosses; error bars, dark dashed line). 2017: (C) Populations with reduced susceptibility from Campinas and Marília. (D) Resistant population from Santos and susceptible populations from Campinas and Marília. Locomotor activity of susceptible Rockefeller strain in 2016 and 2017 is represented in A, B, and C by a shaded grey area with dashed error bar. White bar represents the photophase and black bar the scothophase. ZT: Zeitgeber time; ZTO: time the light turns on; ZT12: time the light turns off.

\section{DISCUSSION}

Ae. aegypti resistant populations presented increased locomotor activity when compared to two populations with reduced susceptibility and to the susceptible Rockefeller laboratory strain. We also verified a temporal variation in the locomotor activity of both reduced susceptibility populations (Campinas and Marília): these populations showed lower locomotor activity than Santos and Ribeirão Preto resistant populations in 2016, but not in 2017. Chemical insecticides are still widely used to control Ae. aegypti mosquitoes, acting on their central nervous system, especially in axonal regions and at the voltage-gated sodium channel $(\mathrm{NaV})$. Yet, the indiscriminate use of different insecticides classes has spurred random mutations, responsible for the development of insecticide resistance phenotype in different Ae. aegypti populations around the world ${ }^{18,30}$. 
Brito et al. (2013) evaluated several life-cycle aspects in a resistant Ae. aegypti strain with $K d r$ mutations, using the Rockefeller strain as control group. According to the authors, when compared to the susceptible allele, the mutation probably has a deleterious maintenance cost or a higher fitness cost. In their study, the $K d r$ strain showed a significantly increased locomotor activity during the light phase when compared to the control group. Our results corroborate those reported by Brito et al. (2013), as Ae. aegypti populations from Ribeirão Preto and Santos, classified as resistant, showed more locomotor activity than populations with reduced susceptibility and the Rockefeller strain, especially in $2016^{24}$.

The 2016 populations from Campinas, Marília, and Rockefeller showed similar locomotor activity - significantly lower than that presented by the resistant populations from Santos and Ribeirão Preto. However, locomotor activity increased in Campinas and Marília in 2017, presenting significantly different values than the Rockefeller strain but not than Santos populations. This suggests a temporal variation that may be explained by changes in the pyrethroid mortality phenotype of these populations. In 2016, the mortality rate was $67 \%$ for the Campinas population and $96 \%$ for the Marília population; as for 2017, these values were $53 \%$ and $52 \%$, respectively [Macoris MLG unpublished data]. Santos resistant population showed a lower mortality rate (28\% in 2016 and 40\% in 2017) than Campinas and Marília populations [Macoris MLG unpublished data]. This data could justify this population greater locomotor activity in relation to the Rockefeller strain in the two evaluated years, and in relation to populations with reduced susceptibility in 2016.

Previous studies have described temporal variation in resistance alleles frequency for all tested populations. In 2001, Santos showed a 0.24 frequency for the resistant allele 1016Ile ${ }^{19}$. Ten years later, resistant allele frequencies were 0.77 for Campinas, 0.53 for Marília, and 0.86 , for Santos ${ }^{19}$. In 2013, Ribeirão Preto presented a 0.68 frequency for the resistant allele 1016Ile, and 0.80 for 1534Cys [Nakazato BM and Bracco JE unpublished data]. In 2014, the last follow-up data, Campinas and Marília populations presented a 0.63 frequency for both 1016lle and 1534Cys mutations. In the same year, both Santos and Ribeirão Preto populations also presented two fixed mutations (frequency 1.00) ${ }^{15}$. This finding may explain the similar locomotor activity results presented by Santos and Ribeirão Preto populations in 2016.

Few studies investigated the impact of insecticide resistance on Ae. aegypti locomotor activity, either in populations from São Paulo or elsewhere. Thus, our findings may help shedding light on several aspects directly involved in this mosquito's activity, such as blood-feeding, flight, and oviposition. We observed an increased locomotor activity of female Ae. aegypti, possibly contributing biologically to their broader dispersion, greater number of blood meals, or any other aspect affecting arboviruses transmission dynamics. A mosquito vectorial capacity is calculated considering several variables. Host-feeding, for examples, exert greater influence on a pathogen's basic reproductive rate $(R 0)$ than the abundance of mosquitoes ${ }^{31}$. Studies have suggested that the vector-biting rate is the most influential parameter for Zika virus transmission dynamics, causing the virus to invade a susceptible population ${ }^{32}$. DENV-2-infected female Ae. aegypti have been reported to present more locomotor activity than uninfected controls ${ }^{22}$. Such increased activity could raise infected mosquitoes biting rate, which, according to a mathematical model, could unfold into dengue outbreaks with greater numbers of primary and secondary infections and more severe biennial epidemics ${ }^{23}$. Thus, control measures should target reducing the vector-biting rate ${ }^{32}$. Mosquitoes circadian rhythms are mainly regulated by circadian clock neurons in the brain ${ }^{33}$, and mutations at sites in the mosquito central nervous system targeted by molecular pyrethroid are the major causes of resistance to this insecticide class $^{24}$. Considering that, further studies should investigate whether these mutations are also associated with changes in locomotor activity.

Insecticide resistance in Anopheles mosquitoes, the main vectors of Plasmodium species, is a genuine concern throughout Africa, especially regarding Anopheles gambia ${ }^{34}$. Different species of Anopheles mosquitoes resistant to insecticide also pose a concern for malaria control in other continents, including the Americas ${ }^{35}$. Few laboratory studies have compared 
the daily activities of resistant and susceptible Anopheles females ${ }^{36-38}$. Resistant Anopheles gambiae mosquitoes, for example, the main malaria vector in Africa, showed a shift in peak biting periods from 21:00-22:00hrs to 03:00-04:00 hrs ${ }^{36}$. A study evaluated the flight activity of resistant and susceptible Anopheles stephensi females under laboratory conditions ${ }^{37}$, finding resistant females to show lower flight activity in the first two days than susceptible females ${ }^{37}$, differently than that found in our study. Anopheles aquasalis females fed with blood containing Ivermectin also showed a decrease in locomotor activity ${ }^{38}$. Further studies should be conducted on this important subject.

As insecticide-resistant populations pose a growing obstacle to vector control programs, our results may contribute to other studies aimed at elucidating aspects involving insecticide resistance, arbovirus infection, and locomotor activity in this mosquito vector.

\section{CONCLUSIONS}

Ae. aegypti populations with insecticide resistance profile showed increased locomotor activity. In 2017, populations with reduced susceptibility presented an increase in the locomotor activity pattern, indicating a temporal change in relation to the previous year. The locomotor activity pattern in the populations from Campinas and Marília did not differ significantly from that found for Santos resistant population.

Our results indicate that insecticide-resistant Ae. aegypti populations show increased locomotor activity, which may affect their arboviruses transmission dynamics by increasing dispersion, number of blood meals, and other ecological parameters. Such results can shed light on these mechanisms action and effect in the context of an arbovirus epidemic, while helping to improve vector control strategies, innovations, and the epidemiology of this and other viral infections transmitted by Ae. aegypti.

\section{REFERENCES}

1. Braks MAH, Honório NA, Lourenço-de-Oliveira R, Juliano AS, Lounibos LP. Convergent habitat segregation of Aedes aegypti and Aedes albopictus (Diptera: Culicidae) in southeastern Brazil and Florida. J Med Entomol. 2003;40(6):785-94. https://doi.org/10.1603/0022-2585-40.6.785

2. Lima-Camara TN. Activity patterns of Aedes aegypti and Aedes albopictus (Diptera: Culicidae) under natural and artificial conditions. Oecologia. 2010;14(3):737-44.

3. Lounibos LP, Kramer LD. Invasiveness of Aedes aegypti and Aedes albopictus and Vectorial capacity for Chikungunya Virus. J Infect Dis. 2016;214(Suppl 5):453-8. https://doi.org/10.1093/infdis/jiw285

4. Brasil. Diretrizes nacionais para prevenção e controle de epidemias de dengue. 1st ver. ed. Brasília: Ministério da Saúde, 2009. 162 p.

5. Severo OP. Eradication of the Aedes aegypti mosquito from the Americas. Yellow fever, a symposium in commemoration of Carlos Juan Finlay; 1955; The Jefferson Medical College of Philadelphia, United States of America: Thomas Jefferson University; 1955. 20 p.

6. Dick OB, San Martín JL, Montoya RH, del Diego J, Zambrano B, Dayan GH. Review. The History of Dengue Outbreaks in the Americas. Am J Trop Med Hyg. 2012;87(4):584-93. https://doi.org/10.4269/ajtmh.2012.11-0770

7. Magalhães RCS. A erradicação do Aedes aegypti: febre amarela, Fred Soper e saúde pública nas Américas (1918-1968). Rio de Janeiro: Editora Fiocruz, 2016. 420 p. https://doi.org/10.7476/9788575414798

8. Braga IA, Valle D. Aedes aegypti: histórico de controle no Brasil. Epidemiol Serv Saúde. 2007;16(2):113-8. https://doi.org/10.5123/S1679-49742007000200006

9. Brasil. Portaria no 329, de 02 de setembro de 1985. Diário Oficial da Únião. 1985 Set 2 [cited 2018 Apr 10]. Available from: http://bvsms.saude.gov.br/bvs/saudelegis/mapa_gm/1985/ prt0329_02_09_198-5.html 
10. Soderlund DM. Review Pyrethroids, knockdown resistance and sodium channels. Pest Manag Sci. 2008;64(6):610-6.

11. D'amato C, Torres JPM, Malm O. DDT (Dicloro Difenil Tricloroetano); Toxicidade e Contaminação Ambiental - Uma Revisão. Quim Nova. 2002;25(6):995-1008. https://doi.org/10.1590/S0100-40422002000600017

12. Superintendência de Controle de Endemias. Suplemento Especial do Boletim Epidemiológico Paulista. São Paulo: Secretaria da Saúde do Governo do Estado de São Paulo, 2006. 62 p.

13. Macoris MLG, Andrighetti MTM, Wanderley DMV, Ribolla PEM. Impact of insecticide resistance on the field control of Aedes aegypti in the State of São Paulo. Rev Soc Bras Med Trop. 2014;47(5):573-8. https://doi.org/10.1590/0037-8682-0141-2014

14. Macoris MLG, Martins AJ, Andrighetti MTM, Lima JBP, Valle D. Pyrethroid resistance persists after ten years without usage against Aedes aegypti in governmental campaigns: Lessons from São Paulo State, Brazil. PLoS Negl Trop Dis. 2018;12(3):1-18. https://doi.org/10.1371/journal.pntd.0006390

15. World Health Organization. Monitoring and managing insecticide resistance in Aedes mosquito populations: interim guidance for entomologists. Geneva: World Health Organization, 2016. 13 p.

16. Hemingway J, Hanson H. Insecticide Resistance in Insect Vectors of Human Disease. Annu Rev Entomol. 2000;45:371-91. https://doi.org/10.1146/annurev.ento.45.1.371

17. Batista E. Evolução de mutações do gene do canal de sódio associadas à resistência tipo Kdr em populações de Aedes (Stegomyia) aegypti do Estado de São Paulo [master's dissertation]. São Paulo: School of Public Health, University of São Paulo, 2012.

18. Martins AJ, Lima JBP, Peixoto AA, Valle D. Frequency of Val1016lle mutation in the voltage-gated sodium channel gene of Aedes aegypti Brazilian populations. Trop Med Int Health. 200;14(11):1351-5. https://doi.org/10.1111/j.1365-3156.2009.02378.x

19. Linss JGB, Brito LP, Garcia GA, Araki AS, Bruno RV, Lima JBP, et al. Distribution and dissemination of the Val1016lle and Phe1534Cys Kdr mutations in Aedes aegypti Brazilian natural populations. Parasit Vectors. 2014;7(25):1-11. https://doi.org/10.1186/1756-3305-7-25

20. Saunders DS. Insect Clocks, Third edition. Elsevier Science. University of Edinburgh. 1st rev. ed. Amsterdam: Elsevier, 2002. 576 p.

21. Lima-Camara TN, Lima JBP, Bruno RV, Peixoto AA. Effects of insemination and blood-feeding on locomotor activity of Aedes albopictus and Aedes aegypti (Diptera: Culicidae) females under laboratory conditions. Parasit Vectors. 2014;7(304):1-8. https://doi.org/10.1186/1756-3305-7-304

22. Lima-Camara TN, Bruno RV, Luz PM, Castro MG, Lourenço-de-Oliveira R, Sorgine MHF, et al. Dengue Infection Increases the Locomotor Activity of Aedes aegypti Females. PLoS One. 2011;6(3):e17690. https://doi.org/10.1371/journal.pone.0017690

23. Luz PM, Lima-Camara TN, Bruno RV, Castro MG, Sorgine, MHF, Lourenço-de-Oliveira R, et al. Potential impact of a presumed increase in the biting activity of dengue-virus-infected Aedes aegypti (Diptera: Culicidae) females on virus transmission dynamics. Mem Inst Oswaldo Cruz. 2011;106(6):755-8. https://doi.org/10.1590/S0074-02762011000600017

24. Brito LP, Linss JGB, Lima-Camara TN, Belinato TA, Peixoto AA, Lima JBP, et al. Assessing the Effects of Aedes aegypti kdr Mutations on Pyrethroid Resistance and Its Fitness Cost. PLoS One. 2013;8(4):e60878. https://doi.org/10.1371/journal.pone.0060878

25. Rosato E, Kyriacou CP. Analysis of locomotor activity rhythms in Drosophila. Nat Protoc. 2006;1(2):559-68. https://doi.org/10.1038/nprot.2006.79

26. Moore-Ede M, Sulzman FM, Fuller CA. The clocks that time us: physiology of the circadian timing system. Cambridge: Harvard University Press, 1984. https://doi.org/10.1152/ajpregu.1986.250.5.R737

27. Lima-Camara TN, Codeço CT, Honório NA, Bruno RV, Peixoto AA, Lounibos LP. Male accessory gland substances from Aedes albopictus affect the locomotor activity of Aedes aegypti females. Mem Inst Oswaldo Cruz. 2013;108(Suppl. 1):18-25. https://doi.org/10.1590/0074-0276130381

28. Alexander N. Review: analysis of parasite and other skewed counts. Trop Med Int Health. 2012;17(6): 684-93. https://doi.org/10.1111/j.1365-3156.2012.02987.x

29. Taylor B, Jones MD. The circadian rhythm of flight activity in the mosquito Aedes aegypti (L.): the phase-setting effects of light-on and light-off. J Exp Biol. 1969;51(1):59-70. 
30. Braga IA, Valle D. Aedes aegypti: Insecticides, Mechanisms of Action and Resistance. Epidemiol Serv Saúde. 2007;16(4):279-93. https://doi.org/10.5123/S1679-49742007000400006

31. Lounibos LP, Kramer LD. Invasiveness of Aedes aegypti and Aedes albopictus and Vectorial Capacity for Chikungunya Virus. J Infect Dis. 201615;214(Suppl 5):453-458. https://doi.org/10.1093/infdis/jiw285

32. Wachira CM, Lawi OG, and Malinzi J. A spatiotemporal model on the transmission dynamics of Zika virus disease. Asian J Math. 2018;10(4):1-15. https://doi.org/10.9734/ARJOM/2018/43944

33. Meirelles-Filho ACA, Kyriacou CP. Circadian rhythms in insect disease vectors. Mem Inst Oswaldo Cruz. 2013;108(Suppl. 1):48-58. https://doi.org/10.1590/0074-0276130438

34. Ranson H, Lissenden N. Insecticide Resistance in African Anopheles Mosquitoes: A Worsening Situation that Needs Urgent Action to Maintain Malaria Control. Trends Parasitol. 2016;32(3):187-196. https://doi.org/10.1016/j.pt.2015.11.010

35. Silva GL, Pereira TN, Ferla NJ, Silva OS. The impact of insecticides management linked with resistance expression in Anopheles spp. populations. Cienc Saude Colet. 2016;21(7):2179-88. https://doi.org/10.1590/1413-81232015217.00922015

36. Githinji EK, Irungu LW, Ndegwa PN, Machani MG, Amito RO, Kemei BJ, et al. Impact of Insecticide Resistance on P. falciparum Vectors' Biting, Feeding, and Resting Behaviour in Selected Clusters in Teso North and South Subcounties in Busia County, Western Kenya. J Parasitol Res. 2020;2020:9423682. https://doi.org/10.1155/2020/9423682

37. Rowland M. Activity and mating competitiveness of $\gamma \mathrm{HCH} /$ dieldrin resistant and susceptible male and virgin female Anopheles gambiae and An.stephensi mosquitoes, with assessment of an insecticide-rotation strategy. Med Vet Entomol. 1991;5(2): 207-22. https://doi.org/10.1111/j.1365-2915.1991.tb00543.x

38. Sampaio VS, Rivas GBS, Kobylinski K, Pinilla YT, Pimenta PFP, Lima JBP, et al. What does not kill it makes it weaker: effects of sub-lethal concentrations of ivermectin on the locomotor activity of Anopheles aquasalis. Parasit Vectors. 2017;10(10):623. https://doi.org/10.1186/s13071-017-2563-0

Funding: Fundação de Amparo à Pesquisa do Estado de São Paulo (FAPESP), Processo número 2016/12140-0, vigência 2016-2018. Bolsa de mestrado: Conselho Nacional de Desenvolvimento Científico e Tecnológico (CNPq). Processo número 155524/2016-0, vigência 2016-2018.

Authors' Contribution: Study design and planning: BMN, MLGM, TNLC; Data collection, analysis and interpretation: BMN, TNLC; Manuscript drafting or review: BMN, MLGM, PRU, TNLC; Approval of the final version: BMN, MLGM, PRU, TNLC; Public responsibility for the content of the article: BMN, MLGM, PRU, TNLC.

Conflict of Interest: The authors declare no conflict of interest. 